\title{
Low-Cycle Fatigue of Ultra-Fine-Grained Cryomilled 5083 Aluminum Alloy
}

\begin{abstract}
J.L. WALLEY, E.J. LAVERNIA, and J.C. GIBELING
The cyclic deformation behavior of cryomilled (CM) AA5083 alloys was compared to that of conventional AA5083-H131. The materials studied were a 100 pct CM alloy with a Gaussian grain size average of $315 \mathrm{~nm}$ and an alloy created by mixing 85 pct $\mathrm{CM}$ powder with $15 \mathrm{pct}$ unmilled powder before consolidation to fabricate a plate with a bimodal grain size distribution with peak averages at $240 \mathrm{~nm}$ and $1.8 \mu \mathrm{m}$. Although the ultra-fine-grain (UFG) alloys exhibited considerably higher tensile strengths than those of the conventional material, the results from plastic-strain-controlled low-cycle fatigue tests demonstrate that all three materials exhibit identical fatigue lives across a range of plastic strain amplitudes. The CM materials exhibited softening during the first cycle, similar to other alloys produced by conventional powder metallurgy, followed by continual hardening to saturation before failure. The results reported in this study show that fatigue deformation in the CM material is accompanied by slight grain growth, pinning of dislocations at the grain boundaries, and grain rotation to produce macroscopic slip bands that localize strain, creating a single dominant fatigue crack. In contrast, the conventional alloy exhibits a cell structure and more diffuse fatigue damage accumulation.
\end{abstract}

DOI: $10.1007 / \mathrm{s} 11661-009-9971-5$

(C) The Author(s) 2009. This article is published with open access at Springerlink.com

\section{INTRODUCTION}

ULTRA-FINE-GRAIN (UFG) and nanocrystalline (NC) materials have generated both practical and scientific interest because of the novel properties that these materials exhibit. Research on bulk UFG metals, formed by severe plastic deformation (SPD) methods, has been driven by the desire to make alloys with superior strength consistent with the Hall-Petch relationship. ${ }^{[1]}$ Research has shown that various UFG materials exhibit different hardening and deformation mechanisms when subjected to monotonic loading. ${ }^{[2,3]}$ However, the application of UFG materials in mechanical or structural designs is not only dependent on strength but also on properties such as corrosion resistance, ductility, fatigue resistance, formability, machinability, and welding characteristics. Fatigue resistance is a measure of a material's ability to resist damage accumulation and crack initiation under cyclic loading. Since fatigue resistance is dependent on the microstructural mechanisms controlling plastic deformation and damage accumulation, prior research has raised questions of whether the fatigue resistance of these novel UFG alloys would be adequate for many applications. ${ }^{[4]}$ In addition, damage accumulation is a

J.L. WALLEY, Graduate Student, is with the Department of Materials Science and Engineering, The Ohio State University, Columbus, $\mathrm{OH}$ 43210. E.J. LAVERNIA and J.C. GIBELING, Professors, are with the Department of Chemical Engineering and Materials Science, University of California, Davis, CA 95616. Contact e-mail: jcgibeling@ucdavis.edu

Manuscript submitted July 25, 2008.

Article published online September 12, 2009 function of plastic deformation, and as such, low-cycle fatigue testing at high stress levels, under constant plastic strain control, would be advantageous for further study into the active deformation mechanisms in UFG alloys.

Methods for creating UFG alloys include but are not limited to SPD by equal channel angular extrusion (ECAE), high pressure torsion, and high energy ball milling, also known as mechanical alloying. ${ }^{[5]}$ Although limited research has been conducted into the fatigue behaviors of these materials, most published studies describe work conducted with ECAE materials. ${ }^{[4,6-12]}$ Low-cycle fatigue testing of ECAE metals has led to the conclusion that the fatigue lives of these UFG metals are only 20 to 50 pct of their coarse grain conventional counterparts, although a recovery heat treatment of these metals increases their fatigue lives. ${ }^{[4]}$

Research into monotonic properties has shown that processing methods greatly change the final mechanical properties of UFG materials, ${ }^{[12,13]}$ so it is not possible to make generalized predictions regarding the fatigue behavior of all UFG materials based solely on data collected for ECAE materials. Therefore, the goal of this study was to examine the fatigue resistance and deformation mechanisms active during low-cycle fatigue testing of two UFG AA5083 alloys created by the high-energy ball milling process known as cryomilling. The cryomilling process creates powder of NC grain size from a desired alloy by using milling balls to fracture and reweld the starting powder at liquid nitrogen temperatures. The NC powder is than consolidated by traditional powder metallurgy techniques to produce bulk UFG alloys ${ }^{[14]}$ of sufficient volume to enable conventional mechanical testing. 


\section{EXPERIMENTAL PROCEDURES}

\section{A. Description of Materials}

The two UFG AA5083 alloys were processed by consolidating cryomilled $(\mathrm{CM})$ powder to produce alloys with different grain size distributions for comparison to conventional AA5083-H131, which is a strain-hardened, solid solution alloy with a grain size of $140 \mu \mathrm{m}$. One UFG alloy was created by consolidating 100 pct cryomilled (100 pct CM) powder by quasiisostatic pressing followed by rolling to produce a 0.75 -in.-thick plate with average grain size of $315 \mathrm{~nm}$. The other UFG plate was produced by hot isostatic pressing a mixture of $85 \mathrm{wt}$ pct $\mathrm{CM}$ powder with $15 \mathrm{wt}$ pct unmilled (UM) powder $(85 / 15$ pct CM/UM), which was subsequently rolled to produce a 0.5 -in-thick plate with a bimodal grain structure with size distributions centered at $240 \mathrm{~nm}$ and $1.8 \mu \mathrm{m}$. In both UFG alloys, the microstructure consisted of nominally equiaxed grains with high-angle grain boundaries and limited preferred orientation with respect to the forging direction. ${ }^{[15]}$ Compositions of all materials are listed in Table I, where the compositions of the UFG alloys were measured from the powders, and the composition of the AA5083-H131 alloy is the nominal specification. In addition, the data presented in Table I demonstrate that the UFG alloys have considerably higher strengths but similar tensile elongations compared to conventional AA5083-H131. ${ }^{[16]}$ Density measurements were performed on both of the consolidated UFG alloys using the method described by Newbery et al. ${ }^{[17]}$ Measurements indicate that the 100 pct CM alloy has a slightly higher density $\left(2.675 \mathrm{gm} / \mathrm{cm}^{3}\right)$ than the conventional plate $\left(2.656 \mathrm{gm} / \mathrm{cm}^{3}\right),{ }^{[17]}$ while the $85 / 15$ pct CMUM alloy has a slightly lower density of $2.635 \mathrm{gm} / \mathrm{cm}^{3}$. ${ }^{[18]}$ Pores less than $1 \mu \mathrm{m}$ in diameter were present in both materials. The fact that the density measurement for the 100 pet CM alloy is greater than that for the wrought material is attributed to the presence of carbide, nitride, and oxide dispersoids. ${ }^{[18]}$

\section{B. Specimen Preparation}

Cylindrical test specimens were electrodischarge machined from the plates with the loading direction parallel to the primary rolling direction and then $\mathrm{CNC}$ turned to ASTM-E606 standard specifications ${ }^{[19]}$ with nominal gage diameter of $3.175 \mathrm{~mm}$ and gage length of $10.16 \mathrm{~mm}$. After machining, the specimens were hand polished on a lathe using 600- to 2500 -grit $\mathrm{SiC}$ paper and 3-, 1-, and $0.25-\mu \mathrm{m}$ diamond paste. The samples were polished so that the final scratch size of $125 \mathrm{~nm}$ was less than the grain size of the materials.

\section{Low-Cycle Fatigue Testing}

The fatigue tests were conducted on a fully automated, closed loop servohydraulic testing system described in detail elsewhere. ${ }^{[20]}$ The actuator system and hydraulic collet grips were aligned to limit bending strains to $\pm 10 \mu \varepsilon$ in the gage section of the specimens. Strain was monitored with a 7.6- $\mathrm{mm}$ gage length extensometer attached to the specimens with elastic bands, and load was determined from a $4448 \mathrm{~N}$ load cell.

All tests were conducted at room temperature under real-time plastic strain control, using a personal computer with MTS TestStar control electronics. ${ }^{[15,21]}$ Tests were conducted at plastic strain amplitudes in the range of 0.1 and 0.7 pct at a constant plastic strain rate of $10^{-3} \mathrm{~s}^{-1}$. All tests were conducted until the specimen failed by fracture or the load had decreased to 20 pct of the peak load on the initial cycle.

Testing under plastic strain control requires accurate elastic modulus values both near zero loading and beyond the standard 0.2 pct yield strength. In particular, Sommer et al. demonstrated that high-strength materials require the use of a nonlinear (stress dependent) elastic modulus. ${ }^{[22]}$ A nonlinear elastic modulus corresponds to a third-order approximation of the interatomic energy producing a quadratic relationship between stress and elastic strain. From this relationship, plastic strain can be calculated as the total strain minus the elastic strain: ${ }^{[22,23]}$

$$
\varepsilon_{\text {plastic }}=\varepsilon_{\text {total }}-\frac{\sqrt{E_{o}^{2}+4 k \sigma}-E_{o}}{2 k}
$$

Accurate values for $E_{o}$ and $k$ were determined from static loading and subsequently refined under cyclic loading by an iterative process to produce vertical loading and unloading in the stress $v s$ plastic strain plot. A summary of the $E_{o}$ and $k$ values used in this study is given in Table II.

Table II. Nonlinear Elastic Parameters

\begin{tabular}{llcc}
\hline Material & \multicolumn{1}{c}{$\Delta \varepsilon_{p} / 2$} & $E_{\mathrm{o}}(\mathrm{GPa})$ & $k(\mathrm{GPa})$ \\
\hline AA5083-H131 & 0.1 to 0.7 pct & 72.5 & -150 \\
$100 \mathrm{CM}$ & 0.1 & 73.25 & -170 \\
& 0.2 to 0.7 pct & 72.5 & -170 \\
$85 / 15 \mathrm{CM} / \mathrm{UM}$ & 0.1 to 0.7 pct & 73.25 & -200 \\
& 0.2 to & -200 \\
\hline
\end{tabular}

Table I. Tensile Properties and Alloy Composition (Presented in Weight Percent Except H, Which is Presented in Parts per Million) for the Three Materials Studied

\begin{tabular}{lcccccccccccc}
\hline Material & $\begin{array}{c}0.2 \mathrm{Pct} Y S \\
(\mathrm{MPa})\end{array}$ & $\begin{array}{c}\text { UTS } \\
(\mathrm{MPa})\end{array}$ & $\begin{array}{c}\text { Elongation } \\
(\mathrm{Pct})\end{array}$ & $\mathrm{Mg}$ & $\mathrm{Mn}$ & $\mathrm{Fe}$ & $\mathrm{Cr}$ & $\mathrm{H}$ & $\mathrm{O}$ & $\mathrm{N}$ & $\mathrm{C}$ & $\mathrm{Al}$ \\
\hline AA5083-H131 & 286 & 286 & 10.8 & 4.9 & 1.0 & 0.4 & 0.25 & 1.3 & 0.003 & 0.0005 & 0.001 & bal \\
$100 \mathrm{CM}$ & 441 & 482 & 10.7 & 4.60 & 0.47 & 0.21 & 0.06 & 9.6 & 0.49 & 0.44 & 0.15 & $\mathrm{bal}$ \\
$85 / 15 \mathrm{CM} / \mathrm{UM}$ & 380 & 450 & 11 & 4.16 & 0.63 & 0.28 & 0.07 & 16.9 & 0.40 & 0.46 & 0.16 & bal \\
\hline
\end{tabular}




\section{Microscopy}

Failed specimens were examined using scanning electron microscopy (SEM). Information regarding crack nucleation could be determined from the fracture surfaces and deformation and cracking seen on the polished gage section near the fracture surface. Three-millimeter discs were sectioned from planes normal to the fatigue loading axis of specimens tested to saturation at both 0.2 and 0.6 pct plastic strain amplitudes. Specimens were then mechanically polished, dimpled, and ion milled to be electronically transparent for transmission electron microscopy (TEM) analysis. Observations were made on the similarities and differences of the deformed microstructure related to implications for understanding the active deformation mechanisms.

\section{RESULTS AND DISCUSSION}

\section{A. Hysteresis Loop Shape}

Early in the investigation, it was determined that for all three material types, a linear elastic modulus produced asymmetrically shaped hysteresis loops in the true stress-true plastic strain regime; in particular, curved or unequal slopes for unloading along the tensile and compressive portions of the loops. These distortions are similar to those reported by other researchers ${ }^{[22-24]}$ and were eliminated by calculating the plastic strain as a function of a nonlinear elastic modulus (Eq. [1]), producing vertical unloading portions, as seen in Fig. 1 .

\section{B. Cyclic Response}

As noted earlier, each material type was tested at a number of plastic strain amplitudes between 0.1 and 0.7 pct plastic strain. Representative stress response

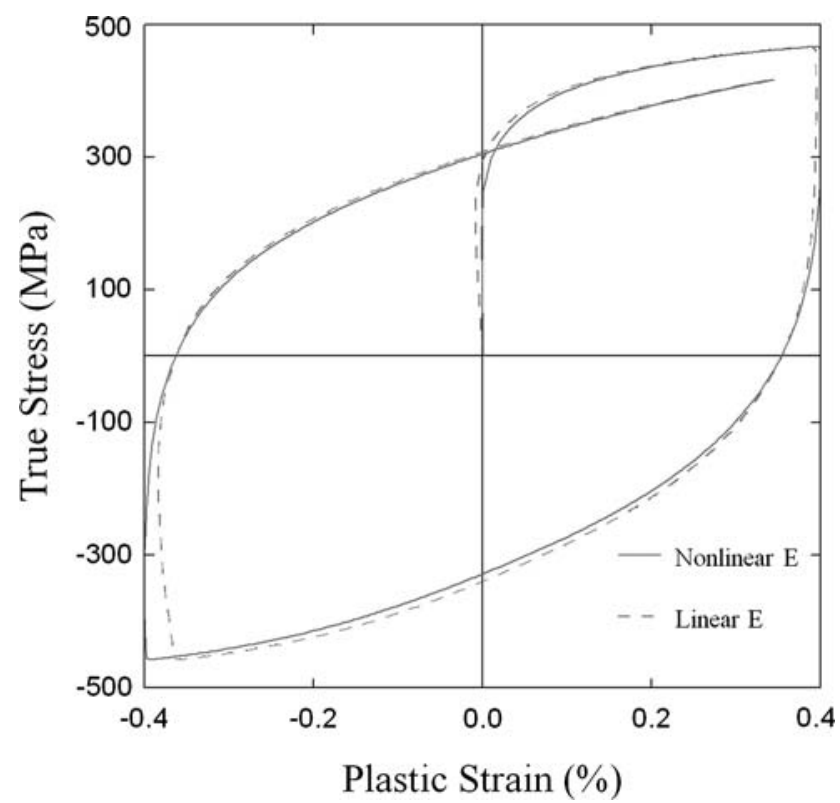

Fig. 1-100 pct CM, hysteresis loop shape as a function of the form of modulus used for calculating plastic strain. curves for the different material types at the same applied plastic strain amplitude are presented in Fig. 2. Both the compression and tension peak stresses are plotted for comparison.

The conventional AA5083-H131 alloy exhibited some asymmetry between the tension and compression peak stresses at the start of the fatigue test. Specimens typically hardened by about 15 pct from the initial cycle to saturation before failure. The specimens typically hardened more rapidly on the compression portion of the loading cycle, such that at saturation there was no observable tension/compression asymmetry. Failure of this alloy was generally caused by significant crack growth, resulting in a 20 pct drop in peak true stress.

Very similar cyclic responses were observed for both the 100 pet $\mathrm{CM}$ and $85 / 15$ pct $\mathrm{CM} / \mathrm{UM}$ materials, and thus, they can be described together. Both materials exhibited abrupt softening on the tension side after the first quarter cycle, followed by continual hardening prior to a saturation period before failure. The initial softening exhibited by the CM materials is consistent with other MA aluminum alloys and is attributed to the relief of compressive residual stresses produced by the consolidation process. ${ }^{[23,25]}$ High-temperature alloys produced by MA do not exhibit this behavior, because these materials are typically subjected to a heat treatment before fatigue testing. ${ }^{[26]}$ The tension and compression strengths increase at the same rate during cycling, producing a constant amount of tension/compression asymmetry from the second cycle until failure.

\section{Tension/Compression Asymmetry}

In order to quantify the amount of persistent tension/ compression asymmetry observed in the CM materials, the asymmetry factor introduced by $\mathrm{Ma}$ et al. ${ }^{[27]} \mathrm{can}$ be used:

$$
A_{f}=2 \frac{\left|\sigma_{c}\right|-\left|\sigma_{t}\right|}{\left|\sigma_{c}\right|+\left|\sigma_{t}\right|}
$$

where $\sigma_{c}$ and $\sigma_{t}$ are the peak compression and tension stresses, respectively, for a given cycle. This asymmetry

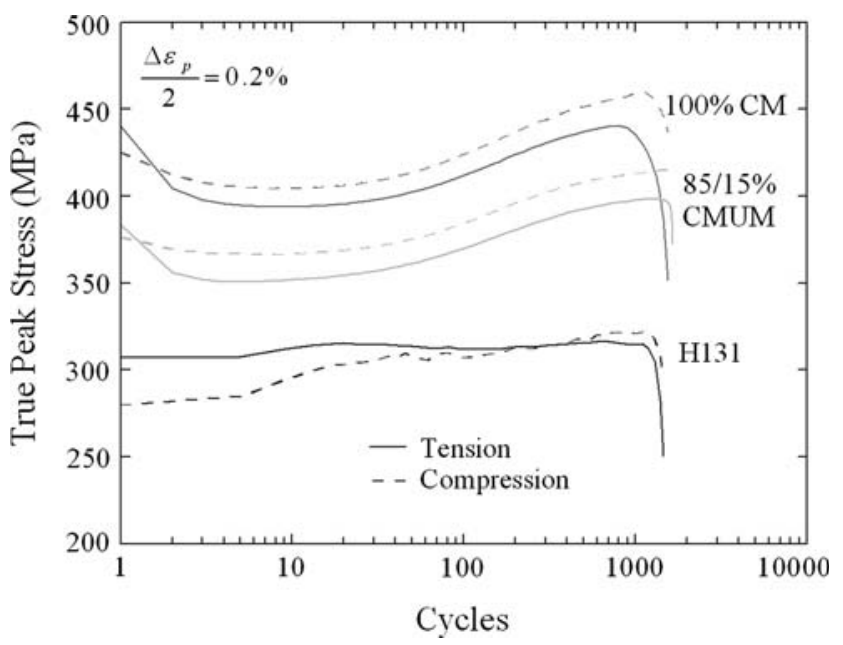

Fig. 2-Representative peak stress response curves for AA5083H131 (H131), 100 pet CM, and 85/15 pet CM/UM alloys. 


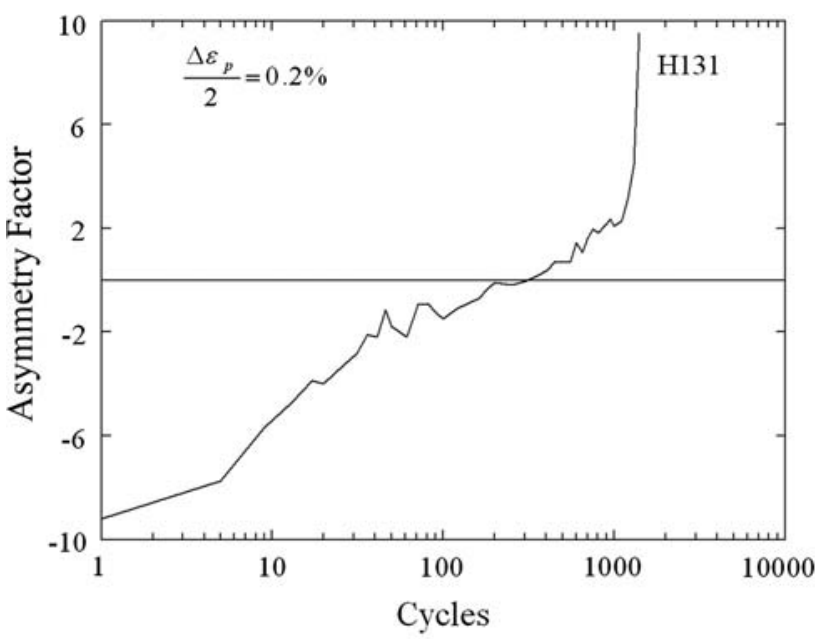

(a)

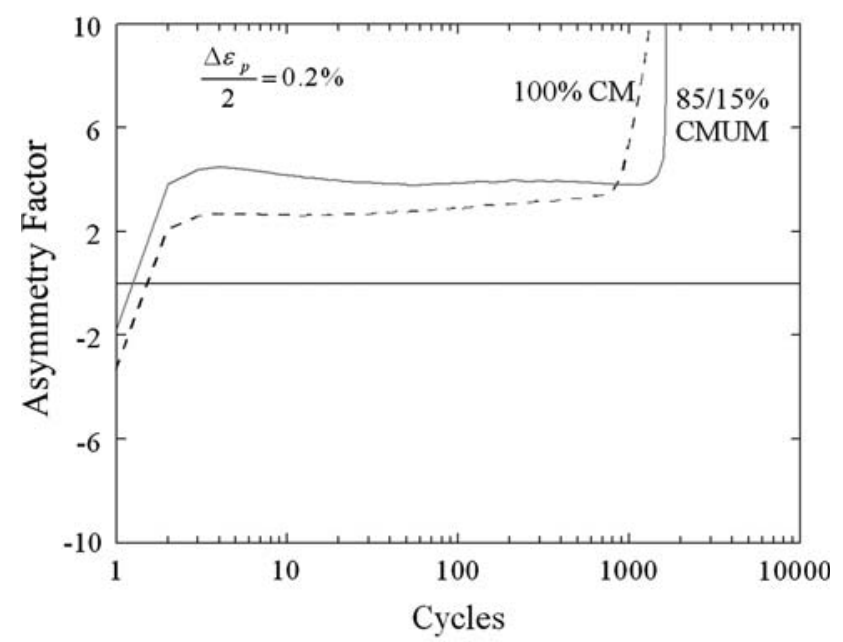

(b)

Fig. 3-Asymmetry factors as a function of number of cycles for $(a)$ AA5083-H131 and $(b)$ the two CM materials corresponding to the data shown in Fig. 2. The rapid increase in the asymmetry factor just prior to failure reflects the influence of a growing fatigue crack on the test results.

factor was calculated as a function of cycle number for each material type. The AA5083-H131 alloy shows a decreasingly negative asymmetry factor as a function of cycle number, leveling off to nearly zero at saturation. The slight positive amount of asymmetry at saturation for the AA5083-H131 sample as seen in Fig. 3(a) is not representative of the zero asymmetry seen at saturation in most tests of this material. The CM alloys exhibit very similar behavior independent of differences in grain size distributions. The alloys exhibit negative asymmetry factors on the first cycle, but the amount of asymmetry levels after the second cycle to a constant amount at saturation Fig. 3(b)).

The asymmetry factors on the initial cycle and at saturation were plotted as a function of applied plastic strain amplitude for both the CM materials (Fig. 4). Even with the scatter in the data, the following trend is observable: the magnitude of the asymmetry factor

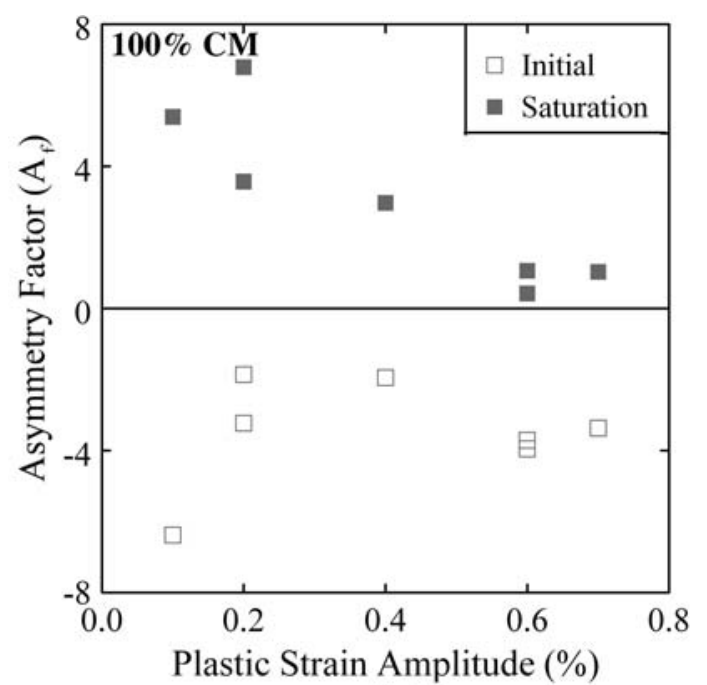

(a)

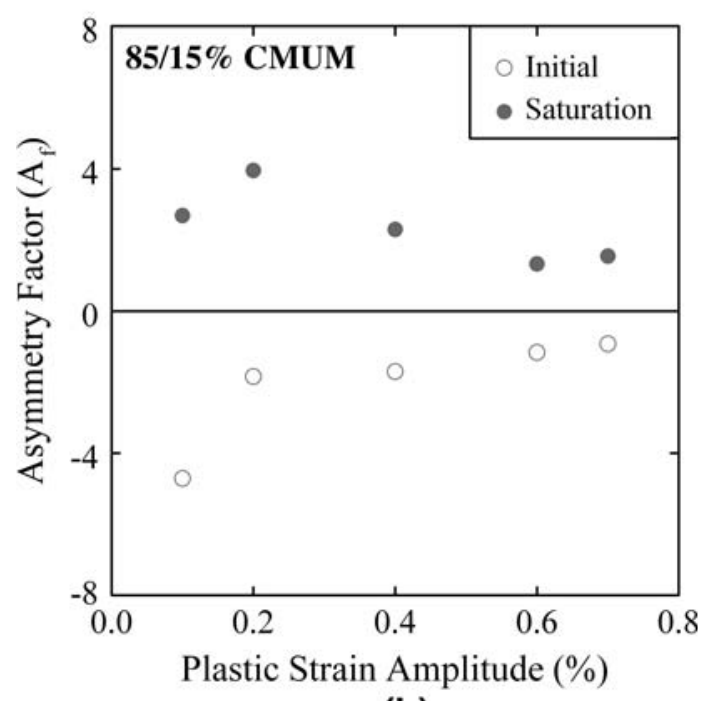

(b)

Fig. 4-Asymmetry factors for the initial cycle and at saturation as a function of applied plastic strain amplitude for the CM alloys.

decreases as plastic strain amplitude increases, and there appears to be a small and constant amount of asymmetry at saturation above 0.6 pet plastic strain. The AA5083-H131 material consistently showed a negative asymmetry factor of -3.5 or greater on the initial cycle and an asymmetry factor of zero at saturation, independent of applied plastic strain amplitude. A previous study also showed that AA5083-H321 (strain hardened and stabilized) exhibited zero asymmetry over the course of cycling. ${ }^{[23]}$

Instances of constant tension/compression asymmetry have been reported for a mechanically alloyed Ni-based superalloy (MA 6000) tested under strain control, ${ }^{[26]}$ for mechanically alloyed aluminum alloys IN-905XL and IN-9052, ${ }^{[23]}$ and for precipitationhardened AA7075-T6 and T651 tempers ${ }^{[24]}$ in plastic strain control tests. In all of these cases, the persistent asymmetry was attributed to distinct microstructural 
features that result in strain localization and inhomogeneous slip. Although the microstructural features leading to localized strain were different, the overall effect on the asymmetry of the hysteresis loops was the same. Thus, the tension/compression asymmetry observed in the UFG materials studied in the present investigation provides evidence of some strain localization during cyclic deformation. In the case of the AA5083-H131, which exhibits a crossover of asymmetry dependent on applied plastic strain amplitude, it is hypothesized that the cumulative deformation eliminates the influence of the initial strain hardening so that at saturation this material behaves in a manner similar to the stabilized AA5083-H321 alloy. This is similar to the behavior exhibited by AA7075-T651 in comparison to the T6 temper. ${ }^{[24]}$

\section{Cyclic Stress-Strain Behavior}

Cyclic stress-strain curves were constructed using the peak stresses at saturation, which were equivalent to the half-life stresses. Fig. 5 shows the cyclic stress strain curves for the three materials tested. The decreasing amount of tension/compression asymmetry with increasing plastic strain amplitude for the CM alloys is evident in this plot. The relative peak stresses for the three materials show that the variations in grain size influence fatigue strength in a manner similar to the effects of the grain size on the monotonic strength (Table I).

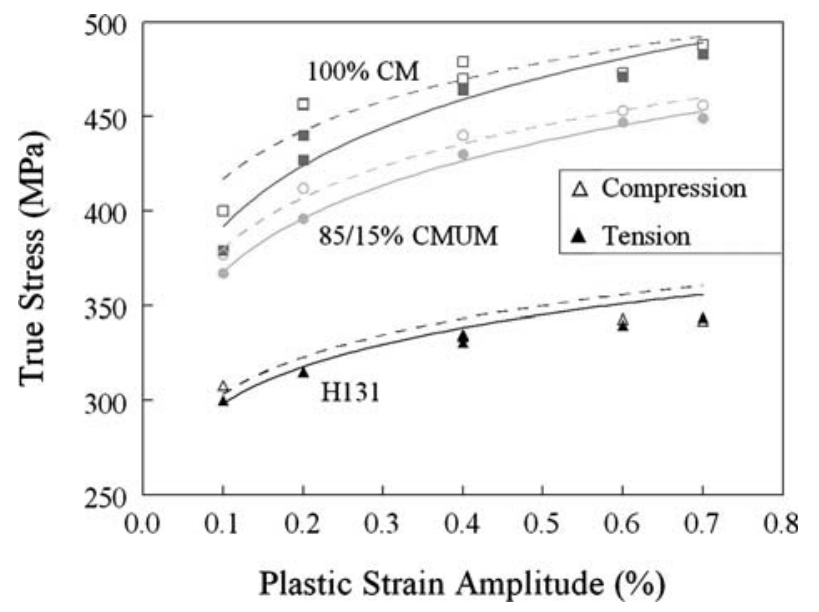

Fig. 5- Cyclic stress-strain curve for the AA5083-H131, 100 pct $\mathrm{CM}$, and $85 / 15$ pet $\mathrm{CM} / \mathrm{UM}$ materials.
The hardening seen in the cyclic stress-strain curve can be characterized by the Holloman power-law relationship: ${ }^{[28]}$

$$
\sigma=k^{\prime}\left(\Delta \varepsilon_{p} / 2\right)^{n^{\prime}}
$$

where $\sigma$ is true stress, $k^{\prime}$ is the intercept, $\Delta \varepsilon_{p} / 2$ is the plastic strain amplitude, and $n^{\prime}$ is the cyclic hardening exponent. Even though there are few data points, the $R^{2}$ values show that a power-law fit is appropriate for the 100 pet $\mathrm{CM}$ and $85 / 15$ pet $\mathrm{CM} / \mathrm{UM}$ alloys but not very accurate for the AA5083-H131 material, which exhibits very little hardening above 0.4 pct plastic strain (Table III).

\section{E. Cyclic Lifetimes}

The cyclic lifetimes for the three materials are presented in Figure 6. It is important to note that the fatigue lifetimes of these three materials are virtually the same at each of the plastic strain amplitudes. Even though the data are scattered for different reasons (buckling tendencies in the H131 material at high plastic strains and the propensity of the CM materials to fail at the extensometer knife edges), the data for each of the three materials fall on lines with $R^{2}$ values greater than 0.97. This unprecedented result shows that UFG alloys can be designed to have equivalent fatigue lives when compared to their conventional coarse-grained counterparts. The slight differences in slopes on the linear fits

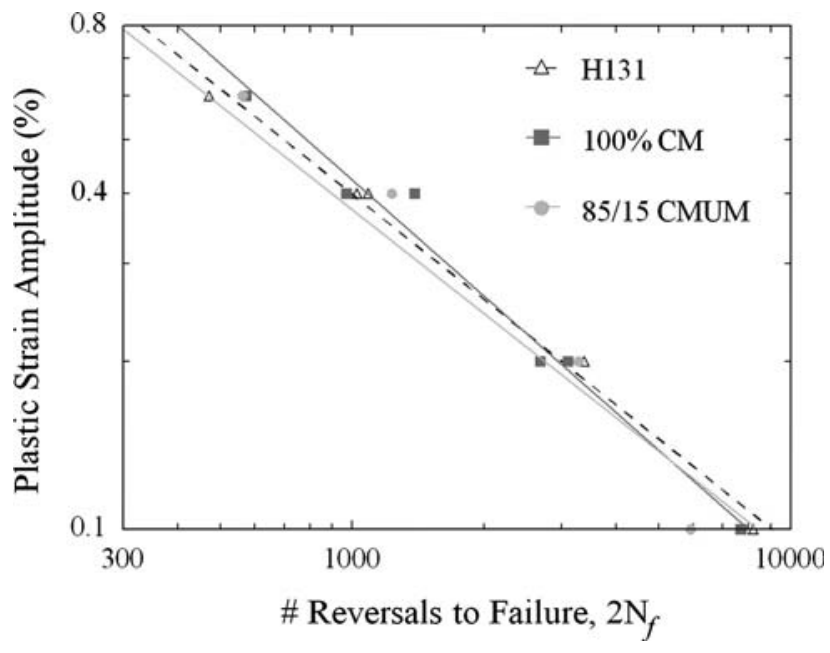

Fig. 6-Coffin-Manson plot of the number of reversals to failure as a function of applied plastic strain amplitude.

Table III. Cyclic Hardening Exponents

\begin{tabular}{|c|c|c|c|c|c|c|}
\hline \multirow[b]{2}{*}{ Parameter } & \multicolumn{2}{|c|}{$\mathrm{H} 131$} & \multicolumn{2}{|c|}{100 Pct CM } & \multicolumn{2}{|c|}{ 85/15 Pct CMUM } \\
\hline & Tension & Compression & Tension & Compression & Tension & Compression \\
\hline$\overline{k^{\prime}(\mathrm{MPa})}$ & 369 & 372 & 510 & 508 & 471 & 747 \\
\hline$n^{\prime}$ & 0.0923 & 0.0881 & 0.114 & 0.0854 & 0.1069 & 0.0976 \\
\hline$R^{2}$ & 0.758 & 0.647 & 0.958 & 0.901 & 0.997 & 0.992 \\
\hline
\end{tabular}




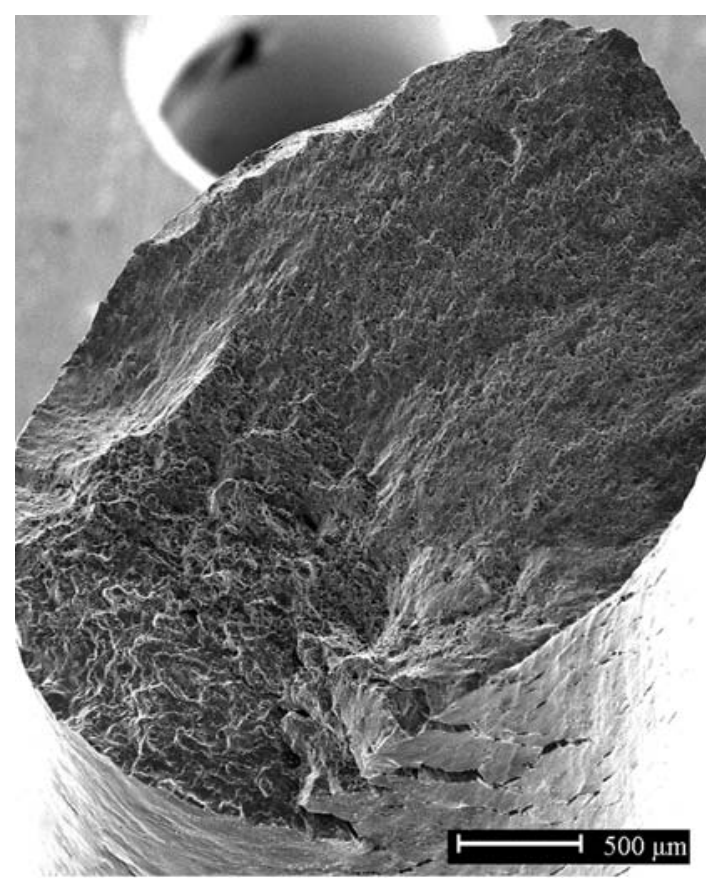

(a)

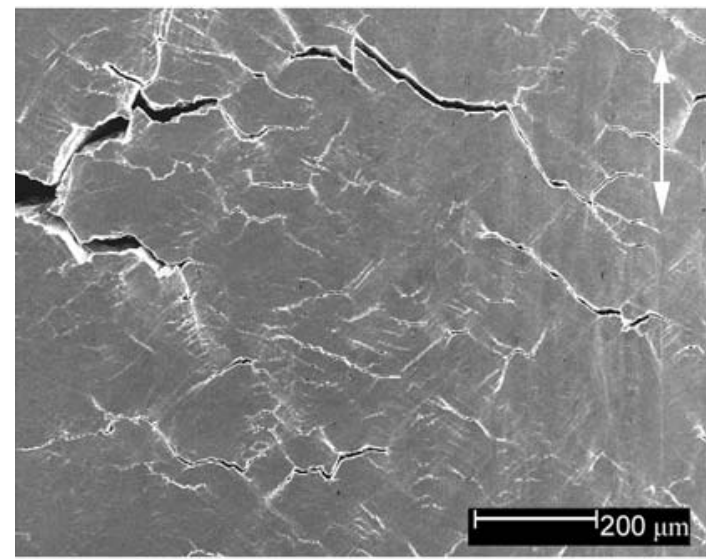

(b)

Fig. 7-SEM images of $(a)$ the fracture surface and $(b)$ polished gage section of the H131 material showing the dominant crack and diffuse cracking at a plastic strain amplitude of 0.6 pct.

are most likely a result of the data scatter rather than actual differences in the dependence of the fatigue life on the number of reversals to failure. If a single linear fit is calculated through all of the data points, the regression equation is $\log \left(\Delta \varepsilon_{p}\right)=1.51 \cdot \log \left(2 N_{f}\right)-0.64$ with an $R^{2}$ value of 0.981 .

\section{F. Microstructural Observations}

There was no discernable distinction between the crack growth patterns at high and low plastic strain amplitudes for the AA5083-H131 material. All samples exhibited substantial, diffuse cracking over the majority of the sample surface. The dominant failure crack grew at close to 45 deg to the loading direction (Fig. 7) and was always accompanied by smaller cracks running both

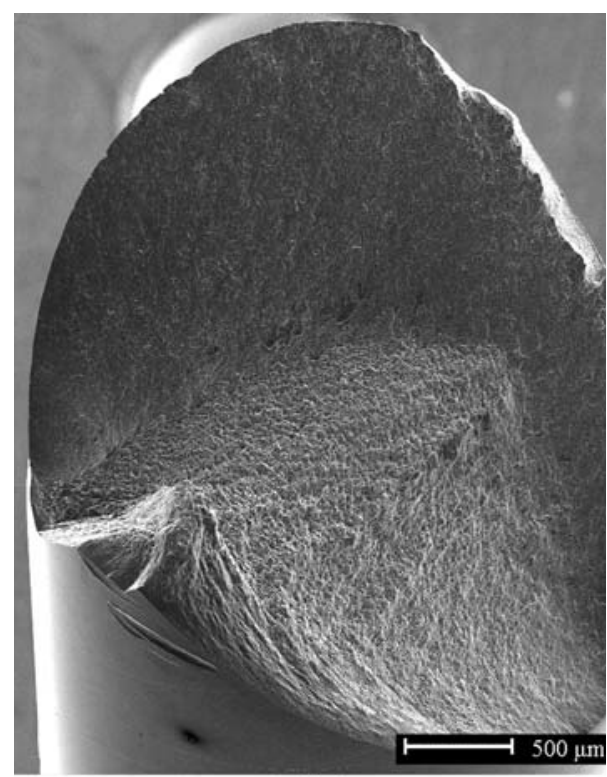

(a)

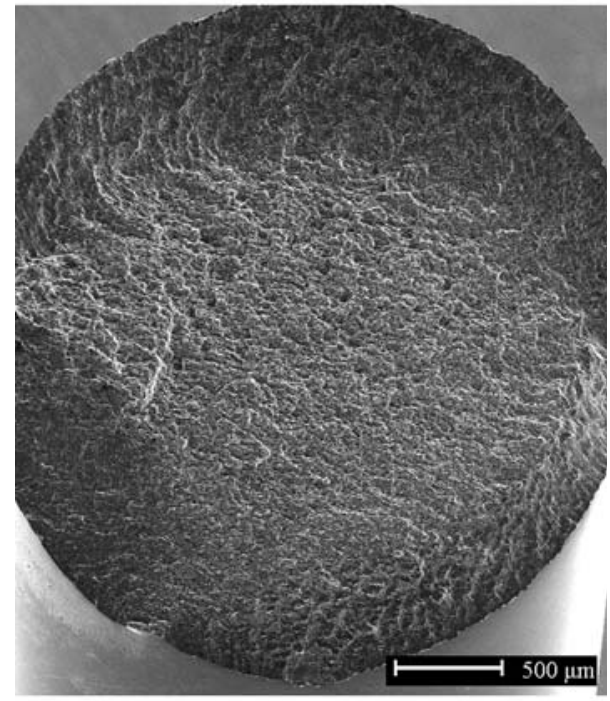

(b)

Fig. 8- SEM images of the fracture surfaces for the (a) 100 pct CM and (b) $85 / 15$ pct $\mathrm{CM} / \mathrm{UM}$ material tests at a plastic strain amplitude of 0.2 pct.

parallel to and at $45 \mathrm{deg}$ to the loading direction. The large grains oriented for limited slip could blunt the dominant crack growth (Fig. 7(b)) and cause the crack to change directions. Observations of the polished surfaces for tests to saturation, instead of failure, also showed signs of diffuse fatigue crack growth.

The two CM materials exhibited similar crack growth patterns. Both materials failed by a single dominant crack; for the 100 pct CM material, this crack ran at $45 \mathrm{deg}$ to the loading direction (Fig. 8(a)), while in the $85 / 15$ pct $\mathrm{CM} / \mathrm{UM}$ material, it ran horizontal to the loading direction for the majority of the sample circumference (Fig. 8(b)). In all cases, porosity was not observed on the fracture surfaces and this is consistent with other published work. ${ }^{[16,29]}$ The dominant features on the fracture surface, striations during slow crack 
propagation, and ductile dimpling of fast fracture are greater than $20 \mu \mathrm{m}$ in size, much larger than the porosity voids observed in both samples. The causes of this difference in crack growth orientation are unknown. The small cracks seen in the lower left corner of Fig. 8(a) are the marks left by the extensometer knife edges. Observations of the polished surfaces showed that the bimodal $85 / 15$ pct CM/UM material did exhibit more diffuse cracking than the 100 pct CM sample, but neither case exhibited cracking as extensive as the coarse-grained material. This confirmed the hypothesis that strain localization must be occurring and causing the tension/compression asymmetry as well as localized cracking. Examining the polished surfaces of tests conducted to saturation, instead of failure, shows little or no fatigue crack growth. This observation is consistent with the current theories that refined grain size decreases the crack nucleation rate in UFG materials. ${ }^{[30]}$

The TEM analysis shows that even though these materials start off with substantially different microstructures before testing, the resulting structures after cycling are very similar. The microstructure of these materials before testing was briefly described earlier and has been presented in detail elsewhere. ${ }^{[31,32]}$ Before cycling, solid solution AA5083-H131 alloy had a grain size of $200 \mu \mathrm{m}$ and contained limited subgrain structure. Strain at a grain boundary can be seen (Fig. 9(a)), but

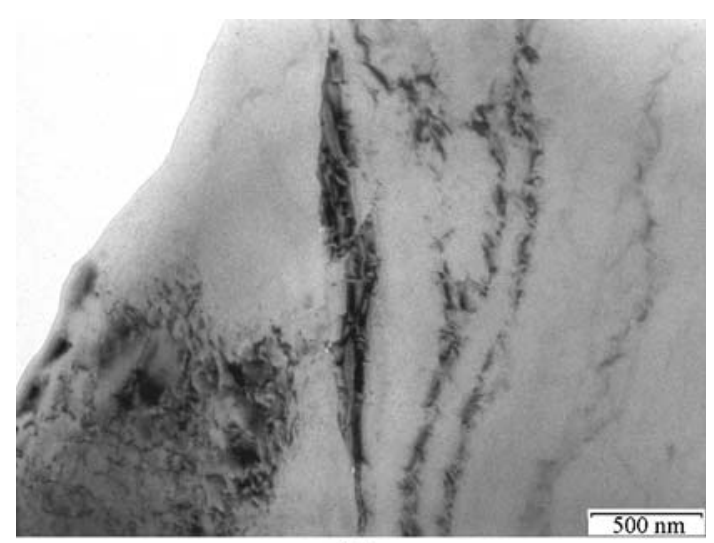

(a)

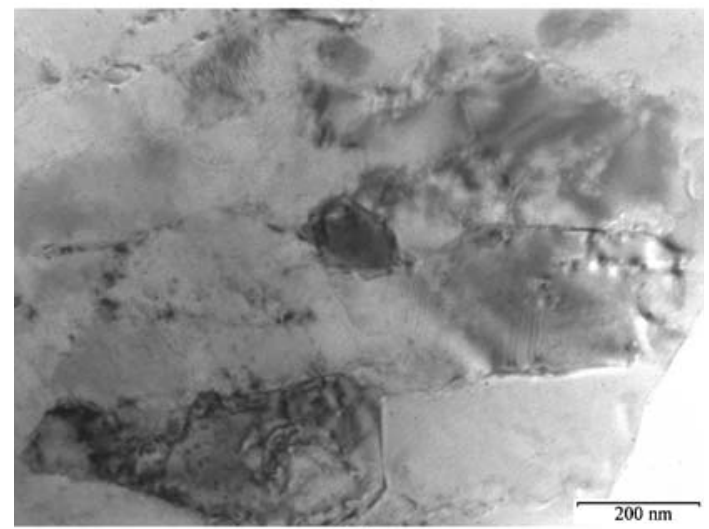

(b)

Fig. 9-(a) As-received grain boundary structure and (b) cell formation after deformation of the conventional AA5083-H131. very little coherent subgrain structure is present in either grain. The image strain at the grain boundary can be seen due to the presence of Moiré fringes. These fringes can be misinterpreted as coherent substructures. After cycling, the AA5083-H131 material has developed a well-defined low-angle grain boundary cell structure in the $500-\mathrm{nm}$ to $1-\mu \mathrm{m}$ size range in which there is significant dislocation accumulation at the cell boundaries. The cells also appear to become elongated and aligned into bands (Fig. 9(b)).

The 100 pct CM material undergoes modest grain growth from $375 \mathrm{~nm}$, Fig. 10(a) to approximately

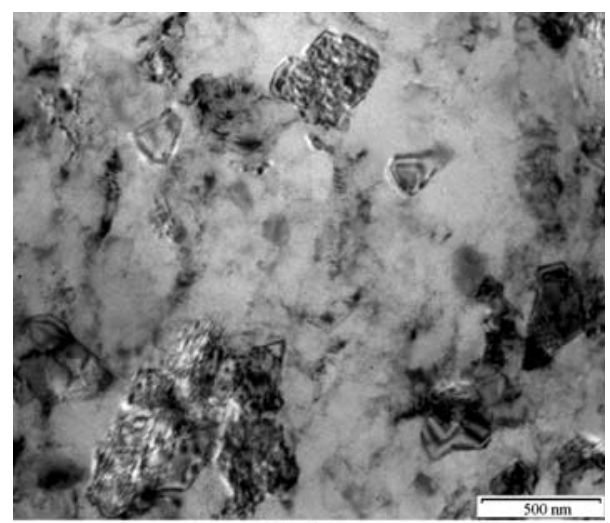

(a)

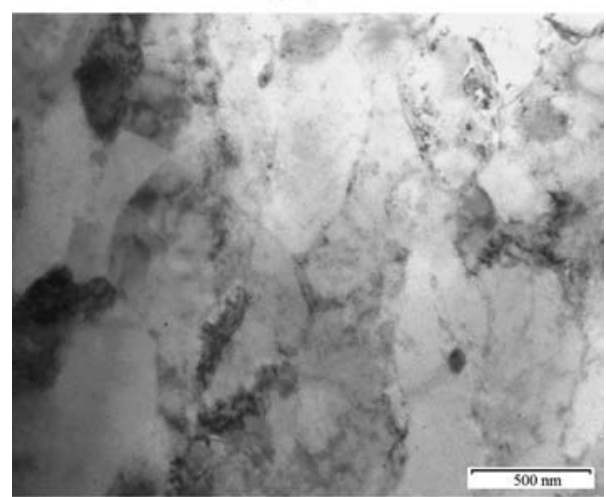

(b)

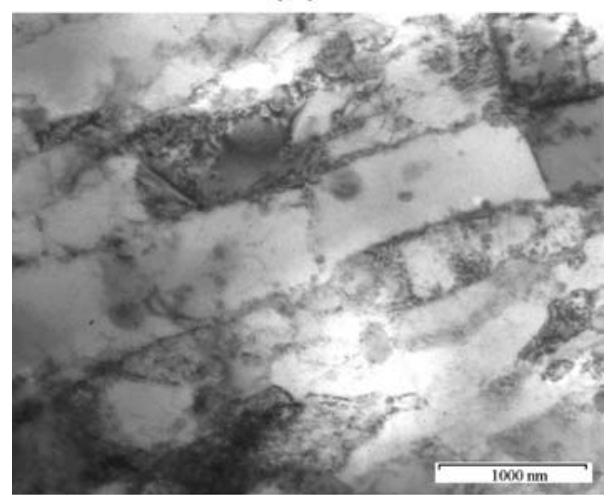

(c)

Fig. 10 - (a) As-received microstructure, (b) grain growth and dislocations tangled at grain boundaries in deformed material, and $(c)$ slip band formation in a 100 pct CM sample tested at a plastic strain amplitude of 0.2 pct. 
$500-\mathrm{nm}$ to $1-\mu \mathrm{m}$ size range to create a structure that is indistinguishable from the H131 cell structure (Fig. 10(b)). The CM material does not form a cell structure consisting of low-angle boundaries; the structure is expected to consist primarily of high-angle grain boundaries, but visual TEM analysis does not readily quantify these differences in structure. A statistical analysis of grain growth for this material after deformation has not been undertaken at this time. Previous research has shown that the thermomechanical stability of the grains of UFG aluminum processed by cryomilling is due to Zener drag by particle pinning. ${ }^{[33-36]}$ As such, it is expected that this grain growth occurs during cycling to saturation and is not the cause of the rapid softening in the first cycle of fatigue. The fatigue structure of the 100 pct CM material exhibits grain rotation to create slip bands that act as localized regions of increased deformation activity (Fig. 10(c)). The development of slip bands with cell-like structures is expected to be the primary mechanism for accommodating plastic strain during cycling.

\section{CONCLUSIONS}

This investigation examined the low-cycle fatigue behavior of three AA5083 alloys processed by different methods: conventionally strain-hardened H131 and two CM materials, 100 pct $\mathrm{CM}$ and $85 / 15$ pet $\mathrm{CM} / \mathrm{UM}$, created by the consolidation of powder after cryomilling. Based on mechanical testing and SEM and TEM observations of the tested specimens, the following conclusions can be drawn.

1. The LCF lifetimes of both of the UFG alloys are equivalent to conventional AA5083-H131 alloy. The equivalent lifetimes are also accompanied by high fatigue strengths in the UFG alloys. Observations of fatigue damage present at saturation lead to the conclusion that crack nucleation occurs more rapidly in the conventional H131 material than in the 100 pct CM material. The high strength of the $\mathrm{CM}$ materials is hypothesized to be the reason behind the delayed crack initiation and would most likely lead to longer $\mathrm{HCF}$ lifetimes consistent with other UFG materials. ${ }^{[31,37]}$

2. The CM materials exhibited cyclic softening on the first cycle before hardening to saturation. The conventionally processed AA5083-H131 alloy exhibited no softening but did harden to saturation before failure. The difference in the cyclic hardening behavior of the $\mathrm{H} 131$ and CM materials is attributed to distinct differences in processing methods. The H131 material was not created by a powder metallurgy process and is not expected to exhibit softening in the first cycle, which is attributed to relief of compressive residual strain left by consolidation of the CM and other mechanically alloyed materials. Modest grain growth observed in the UFG alloys is not expected to contribute to the initial cyclic softening of the material since the softening happens rapidly in the first cycle and deformation-induced grain growth requires greater strains.

3. The CM materials exhibit a persistent amount of tension-compression asymmetry during fatigue through saturation. The persistent asymmetry provides evidence of strain localization in the $\mathrm{CM}$ materials that is not present in the conventional AA5083-H131 alloy.

4. The CM materials exhibit power law hardening, but there may be a hardening threshold above $0.6 \mathrm{pct}$ since the $\Delta \varepsilon_{p} / 2=0.6$ and 0.7 pct tested samples hardened to the same values, indicating the break down of power law hardening theory above a particular plastic strain amplitude.

5. The large grain size of the AA5083-H131 material allows for fatigue damage to diffuse over the whole of the sample with damage following favorably oriented crystallographic planes. In contrast, the UFG size of the CM materials leads to more localized fatigue damage following macroscopic slip planes created by grain rotation.

6. The TEM analysis suggests that the primary mechanisms for accommodating plastic strain during cyclic loading of 100 pct CM material are slight grain growth, pinning of dislocations at the grain boundaries, and grain rotation to produce macroscopic slip bands that localize strain, creating a single dominant fatigue crack. Low-cycle fatigue of AA5083-H131 creates a cell structure by subdividing the bulk grain structure, while the 100 pct CM material undergoes grain growth and grain rotation, two different mechanisms, to produce microstructures of similar scales after cycling. Even though the mechanisms of plastic strain accommodation are different for the AA5083-H131 and 100 pct CM materials, the structure at saturation is dictated by the same fundamental microstructural size.

\section{ACKNOWLEDGMENTS}

This research has been made possible by financial support from the Office of Naval Research, under Contract Nos. N00014-04-1-0370 and N00014-08$1-0405$ and by funding from the University of California, Davis.

\section{OPEN ACCESS}

This article is distributed under the terms of the Creative Commons Attribution Noncommercial License which permits any noncommercial use, distribution, and reproduction in any medium, provided the original author(s) and source are credited.

\section{REFERENCES}

1. T.C. Lowe and Y.T. Zhu: Adv. Eng. Mater., 2003, vol. 5, pp. $373-$ 78.

2. H. Conrad: Metall. Mater. Trans. A, 2004, vol. 35A, pp. 2681-95. 
3. M.A. Meyers, A. Mishra, and D.J. Benson: Progr. Mater. Sci., 2006, vol. 51, pp. 427-556.

4. H.W. Hoppel, M. Kautz, C. Xu, A. Murashkin, T.G. Langdon, R.Z. Valiev, and H. Mughrabi: Int. J. Fatigue, 2006, vol. 28, pp. $1001-10$.

5. C.C. Koch: Nanostructured Materials: Processing, Properties and Potential Applications, Noyes Pub./William Andrew Pub., Norwich, NY, 2002.

6. S.R. Agnew and J.R. Weertman: Mater. Sci. Eng. A, 1998, vol. 244, pp. 145-53.

7. H.Z. Ding, H. Mughrabi, and H.W. Hoppel: Fatigue Fract. Eng. Mater. Struct., 2002, vol. 25, pp. 975-84.

8. T. Hanlon, E.D. Tabachnikova, and S. Suresh: Int. J. Fatigue, 2005, vol. 27, pp. 1147-58.

9. H.J. Maier, P. Gabor, N. Gupta, I. Karaman, and M. Haouaoui: Int. J. Fatigue, 2006, vol. 28, pp. 243-50.

10. V. Patlan, A. Vinogradov, K. Higashi, and K. Kitagawa: Mater. Sci. Eng. A, 2001, vol. 300, pp. 171-82.

11. L.J. Venning, I. Sinclair, and P.A.S. Reed: Mater. Sci. Forum, 2006, vols. 519-521, pp. 1077-82.

12. A. Vinogradov: Mater. Sci. Forum, 2006, vols. 503-504, pp. $267-$ 74.

13. B.Q. Han, F.A. Mohamed, and E.J. Lavernia: Mater. Res. Soc. Symp. Proc., 2004, vol. 821, pp. 1-6.

14. D.B. Witkin and E.J. Lavernia: Progr. Mater. Sci., 2006, vol. 51, pp. $1-60$.

15. J.L. Walley: Master of Science Thesis, University of California, Davis, Davis, CA, 2008.

16. T.D. Topping: "Processing, Mechanical and Microstructural Characterization of Cryomilled Al-Mg Alloys," University of California, Davis, Davis, CA, personal communication, 2007.

17. A.P. Newbery, B. Ahn, R.W. Hayes, P.S. Pao, S.R. Nutt, and E.J. Lavernia: Metall. Mater. Trans. A, 2008, vol. 39A, pp. 2193205.

18. A.P. Newbery: "Project Review: HIPed, HSR-Forged and Rolled 85/15 Blend Plate (MC-07)," University of California, Davis, Davis, CA, 2007.

19. S.A. Arendt: ASTM Standard E606-04: Standard Practice for Strain-Controlled Fatigue Testing, ASTM International, Baltimore, MD, 2005.
20. G.C. Kaschner and J.C. Gibeling: Acta Mater., 2002, vol. 50, pp. 653-62.

21. J.M. Meininger and J.C. Gibeling: Metall. Mater. Trans. A, 1992, vol. 23A, pp. 3077-84.

22. C. Sommer, H.J. Christ, and H. Mughrabi: Acta Metall. Mater., 1991, vol. 39, pp. 1177-87.

23. M.E. Mercer, S.L. Dickerson, and J.C. Gibeling: Mater. Sci. Eng. A, 1995, vol. 203, pp. 46-58.

24. J.M. Meininger, S.L. Dickerson, and J.C. Gibeling: Fatigue Fract. Eng. Mater. Struct., 1996, vol. 19, pp. 85-97.

25. R.T. Chen and E.A. Starke, Jr.: Mater. Sci. Eng., 1984, vol. 67, pp. $229-45$.

26. J. Bressers and E. Artz: High Temp. Alloys for Gas Turbines and Other Applications Part II: High Temperature Low Cycle Fatigue of Inconel MA 6000, D. Reidel Publishing, Dordrecht, Holland, 1986, pp. 1067-80.

27. B.T. Ma, Z.G. Wang, A.L. Radin, and C. Laird: Mater. Sci. Eng. A, 1990, vol. 129, pp. 197-206.

28. S. Suresh: Fatigue of Materials, Cambridge University Press, Cambridge, United Kingdom, 1991.

29. T.D. Topping, A.P. Newbery, S. Zhu, and E.J. Lavernia: Mechanical Behavior of an Ultra-Fine Grained Aluminum Alloy, Poster Session, TMS, Warrendale, PA, 2007.

30. ë. G. Gogoëtìsi: Nanomaterials Handbook, 1st, CRC/Taylor \& Francis, Boca Raton, FL, 2006.

31. M. Hockauf, L.W. Meyer, T. Halle, C. Kuprin, M. Hietschold, S. Schulze, and L. Kruger: Int. J. Mater. Res., 2006, vol. 2006, pp. 1392-1400.

32. A.P. Newbery, B. Ahn, P. Pao, S.R. Nutt, and E.J. Lavernia: Mater. Sci. Forum, 2007, vol. 203, pp. 37-45.

33. B.J. Aikin, D.T. Dickerson, and D.T. Jayne: Scripta Metall., 1994, vol. 30, pp. 119-22.

34. Z. Zhou, J. Lee, S. Dallek, and E.J. Lavernia: J. Mater. Res., 2001, vol. 16, pp. 3451-58.

35. R.W. Hayes, V.L. Tellkamp, and L. E.J.: J. Mater. Res., 2000, vol. 15, pp. 2215-22.

36. E.J. Lavernia, B.Q. Han, and J.M. Schoenung: Mater. Sci. Eng. A, 2008, vol. 493, pp. 207-14.

37. K.S. Kumar, H. Van Swygenhoven, and S. Suresh: Acta Mater., 2003, vol. 51, pp. 5743-74. 